\title{
EFFECT OF Agrobacterium rhizogenesis ON HAIRY ROOTS INDUCTION IN FENNEL (Foeniculum vulgare MILLER)
}

\author{
Nishtman abdi ${ }^{1}$, Ebrahim Dorani Uliaie ${ }^{2 *}$, Ali Bandehagh ${ }^{2}$, Saeed Aharizad $^{3}$ \\ ${ }^{1} \mathrm{Ph} . \mathrm{D}$ student of Molecular genetics and genetic engineering, Faculty of Agriculture, University of Tabriz, Tabriz, Iran \\ $2^{2 *}$ Assistant professor, Department of Plant Breeding and Biotechnology, Faculty of Agriculture, University of Tabriz, Tabriz, Iran \\ ${ }^{3}$ Professor, Department of Plant Breeding and Biotechnology, Faculty of Agriculture, University of Tabriz, Tabriz, Iran
}

Received - March 28, 2017; Revision - June 08, 2017; Accepted - June 29, 2017

Available Online - June 30, 2017

DOI: http://dx.doi.org/10.18006/2017.5(3).384.391

\section{KEYWORDS}

Fennel

Agrobacterium rhizogenes

Hairy root culture

Hairy root induction

Explant type

\begin{abstract}
This study was conducted to access the effects of seven Agrobacterium rhizogenes strains i.e. A4, T4, MSU, TCC15834, 2656, Gm1 and R1000, on the hairy root generation from various explants i.e. hypocotyl, cotyledon, root, stem and leaf of Fennel ecotypes (Bonab, Izmir, Esfahan and Moghan). Results of study revealed that induction of hairy root varies with the A. rhizogenes strains and used explants. Among the various tested combinations, highest root induction was recorded form hypocotyl explants using A4 and TCC 15834 (70 and 67\%, respectively) strains of A. rhizogenes. Response of explant toward hairy root induction and number of the hairy roots per explant was different and decreased from hypocotyl, leaf and cotyledonary explants, respectively. Among the various tested A. rhizogenes strain, TCC 15834 capable to induced hairy Roots development in all ecotypes but most effectively in Izmir (36.66 \pm 0.57$)$ and it was followed by Bonab $(32 \pm 0.44)$, Esfahan $(30 \pm 0.99)$ and Moghan $(16.66 \pm 0.79)$. All transformed hairy root were successfully confirmed by PCR using rolB primers. Further hairy root induction could be proved as an alternative approach for the production of secondary metabolites and its increasing use as model system in metabolic engineering.
\end{abstract}

* Corresponding author

E-mail: uliaie@yahoo.com (Ebrahim Dorani Uliaie)

Peer review under responsibility of Journal of Experimental Biology and Agricultural Sciences.

Production and Hosting by Horizon Publisher India [HPI] (http://www.horizonpublisherindia.in/).

All rights reserved.
All the article published by Journal of Experimental Biology and Agricultural Sciences is licensed under a Creative Commons Attribution-NonCommercial 4.0 International License Based on a work at www.jebas.org.

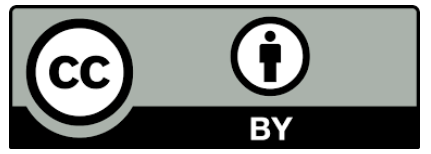




\section{Introduction}

Fennel (Foeniculum vulgare Miller) is an important herbal plant growing in Mediterranean regions and widely used as a vegetable and medicinal crop (Jamshidi et al., 2012). This plant is well known for its anti-inflammatory, antispasmodic, antiseptic, carminative, diuretic and analgesic effect. Its anti-ulcer and antioxidant properties were also well reported by researcher. Further, it is widely used to gastrointestinal and neurological disorders (Birdane et al., 2007; Delaram et al., 2011). The medicinal benefit of fennel is mainly because of essential oils and aromatic compounds which are produced in secretary canals present in all organs of this tree. Among various studied aromatic and volatile compounds, anethole is the main alkaloid and the primary component of its volatile oil (Hnnanlt et al., 1989). Obtaining medicinally important compounds from the wild or cultivated plants is limited due to difficulties in cultivating under field conditions, risk of extinction due to over exploiting plant from natural habits and geopolitical limitation (Verpoorte et al., 2002). In order to overcome these problems, many attempts have been made over last few decades, possibility of producing medicinally important plant compounds through plant tissue or organ cultures is one of the alternate to avoid above mentioned such barriers (Berlin, 1986; Alfermann \& Petersen, 1995). However, in most of the cases, medicinally effective compounds were undetectable or were accumulated at low levels in the in-vitro cultures. Therefore several strategies such as screening and selection of high yield producing cultivars or ecotypes, elicitation and culture of differentiated tissues were developed. In most of the cases several problems were encountered which prevented the development of an economically valuable commercialization of the biotechnologically produced compounds (Verpoorte et al., 2002; $\mathrm{Hu} \& \mathrm{Du}, 2006)$.

A. rhizogenes mediated hairy root production is a valuable tool to overcome the difficulties associated with the in-vitro plant organ cultures and metabolic engineering (Ravishankar \& RamachandraRao, 2000; $\mathrm{Hu} \& \mathrm{Du}, 2006)$. Further, it also considered as a beneficial tool in obtaining fast growing organs with extensive branching and capability of producing the main metabolites of the mother plant or even new metabolites that neither detected in the mother plant nor in other kinds of in vitro cultures (Nader et al., 2006). So far, in vitro studies conducted on the production of the fennel secondary metabolites are mainly based on the callus or cell suspension cultures (Paupardin, 1976; Garcia-Rodriguez et al., 1978). However, plant cell suspension cultures for the production of secondary metabolites have been hampered by several limitations such as low yields of desired compounds, expensive culturing process, application of phytohormones, heterogeneous cell types, lack of storage tissue and products easily degraded by the enzymes released in the media (Davies \& Deroles, 2014). Hairy root cultures have been induced in many plant species which leading to the in vitro production of numerous plant secondary metabolites and pharmacologically active compounds (Bensaddek et al., 2008; Ooi et al., 2013; Nagella et al., 2013; Sharafi et al., 2014; Thwe et al., 2016; Yao et al., 2016). Genetic engineering is a modern tool which regulates the production of secondary metabolism. In order to introduce exogenous genes into plants for increasing the amount of target compounds or to gain insight into the functions of genes, the transformation conditions must first be optimized. However, the success of hairy root induction in plants species depends on various parameters such as the plant species, ecotypes age of the plant tissue (Sevon \& Oksman-Caldentey, 2002), strain of $A$. rhizogenesis and the density of the bacterial suspension (Park \& Facchini, 2000). To the best of our knowledge, several species of the fennel family have been transformed by A. rhizogenes for producing hairy roots in the past (Baranski, 2008), but this is the first report considering the effect of different factors on $A$. rhizogenes transformation of $F$. vulgar. Present study has been focused on the developing an efficient protocol for induction of high frequency hairy root in fennel.

\section{Materials and Methods}

\subsection{Plant material, culture media and conditions}

Seeds of fennel ecotypes (Bonab, Izmir, Esfahan and Moghan) were obtained from a local supplier. Healthy seeds were scrutinized by physical inspection and selected seed were taken for surface sterilization. For surface sterilization, seeds were washed under tap water for 5 minutes, and it was followed by the application of $3 \%$ sodium hypochlorite solution containing $0.1 \%$ Tween-20 for $15 \mathrm{~min}$ and rinsed three times with sterile distilled water. Finally seeds were sterilized with $70 \%$ ethanol for 2 minutes and rinsed again several times with sterile water. Ten sterilized seeds were cultured in individual Petri dishes containing halfstrength of MS media ( $1.5 \%$ sucrose and $5 \mathrm{~g} / \mathrm{l}$ agar). Seeds were left to germinate under a 16/8 h (light/dark) photoperiod for 3-4 weeks. Various explants cotyledon, hypocotyl, root (of one-weekold seedlings) leaf and stem (of two-weeks-old plants) about $1 \mathrm{~cm}$ were excised and used as starting material for co-cultivation with A. rhizogenes.

\subsection{A. rhizogenes strains and Preparation of Inoculum}

Various strains of A. rhizogenes including A4, T4, MSU, TCC15834, 2656, Gm1 and R1000 harboring a Ri plasmid that involved in the root induction process were provided by Dr. A. Mirshamsi (Department of Plant Breeding and Biotechnology, University of Mashhad, Iran). Single colony of the A. rhizogenesis were cultured in $25 \mathrm{ml}$ of $\mathrm{LB}$ medium and incubated at $28^{\circ} \mathrm{C}$ in the dark on a rotary shaker at $120 \mathrm{rpm}$. Bacterial cultures were allowed to grow until the $\mathrm{OD}_{600}$ of 0.3 was obtained. Bacterial suspensions were centrifuged (3000 rpm. for $10 \mathrm{~min}$ ) and obtained pellets were re-suspended in freshly prepared MS liquid medium to obtain the best optical densities $\left(\mathrm{OD}_{600}\right) 0.6$ (tested among $\mathrm{OD}_{600} 0.2-0.8$ ) for inoculation to explants. 


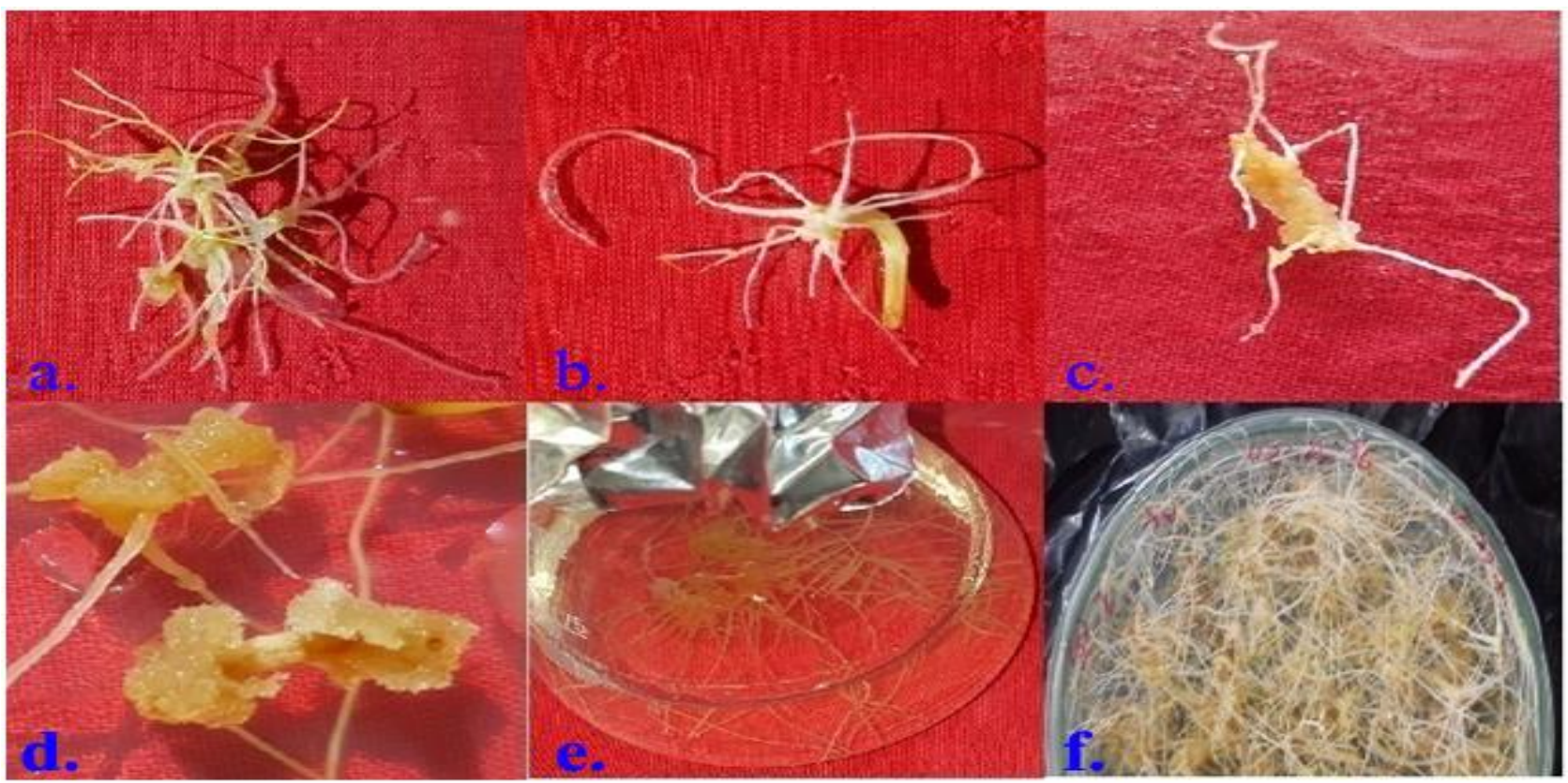

Figure 1. A. rhizogenes mediated transformation of F. vulgare with different Agrobacterium rhizogenes strains for one month

hairy root induction after 2 weeks of inoculation in leaf explants (a), hypocotyl explants (b) and cotyledon explant (c), callus formation in stem explants (d), Three-week-old $C$ transformed root cultures in MS liquid medium (e) and hairy roots induction morphology after one month of inoculation (f)

\subsection{Induction of hairy root culture}

For induction of hairy root culture, each plant part (hypocotyl, cotyledon, root, stem and leaf) were cut in to $1 \mathrm{~cm}$ length and immersed in $10 \mathrm{~mL}$ of the bacterial suspension that prepared 20 min before the inoculation (best time tested among $10-50 \mathrm{~min}$ ). For each explants minimum 30 plant tissue were immersed with bacterial suspension. These inoculated explants were cultured in Petri dishes containing basal MS medium without hormones (5 g/l agar) in the dark for two days. Later on these explants were transferred to fresh MS medium containing $0.5 \mathrm{~g} / \mathrm{l}$ Cefotaxime. Bacteria-free roots were subcultured in $150 \mathrm{ml}$ Erlenmeyer flask containing MS medium (hormone-free) and were used as controls (Figure 1, e).

\subsection{Statistical analysis}

Three fennel ecotypes were evaluated with seven A. rhizogenes strains and five explants in a factorial arrangement based on completely randomized design. Each treatment consisted 10 explants per Petri dish with three replicates. Two parameters viz. induction of hairy root and number of hairy root were measured after one month and analyzed using a two-way analysis of variance (ANOVA) with SAS 9.0 and standard deviation and mean values expressed as mean $\pm \mathrm{SD}$.

\subsection{PCR analysis}

Genomic DNA from putative transformed hairy roots and normal roots was extracted by the cetyl-trimethylamonium bromide
(CTAB) (Murray \&Thampson, 1980). Ri plasmid DNA was extracted from all strains using the SDS/alkalinelysis and used as positive control. For conforming of transgenic roots, polymerase chain reaction (PCR) were used to amplification of $\mathrm{rolB}$ gene for randomly chosen events among all explants specific using $5^{\prime}$ GCTCTTGCAGTGCTAGATTT- 3 ' and 5' -GAA GGT GCA AGC TAC CTC TC- $3^{\prime}$ as the forward and reverse primers, respectively.

\section{Results and Discussion}

\subsection{Establishment of hairy roots}

In the present study, seven strains of A. rhizogenes (A4, T4, Msu, R1000, 2656, Gm1 and TCC 15834) and five explants (hypocotyl, cotyledon, root, stem and leaf) were tested for their ability to induce hairy root on four fennel ecotypes (Bonab, Izmir, Esfahan and Moghan). During study, putative hairy roots were obtained from leaf (Figure 1, a), hypocotyl (Figure 1, b) and cotyledon (Figure 1, c) after 14 days of co-cultivation, but root and stem explants were dead followed by the necrosis of the tissue in all fennel ecotypes. No hairy roots or callus were formed in control explants. Also very few number of explants showed callus-like morphology (Figure 1, d) as reported by others (Moyano et al., 1999). When the hairy roots grew to $2-3 \mathrm{~cm}$ in length, they were excised and subcultured in plant-hormone-free MS liquid medium (figure 1, f). Callus formation was reported lowest in the cases of A. rhizogenes strain $\mathrm{A} 4, \mathrm{~T} 4, \mathrm{MSU}$ and $\mathrm{TCC} 15834$; these strains were also found most effective strains for hairy root induction for all fennel ecotypes. However, other strains (R1000, 2656 and 
Gm1) did not induce any hairy root. Therefore in this study $A$. rhizogenes strains A4, T4, MSU and TCC15834 and explants leaf, hypocotyl and cotyledon explants were found effective in the hairy root generation. The hairy roots were formed from the wounded site of A. rhizogenes infected explants (Figure1). These results are in accordance with the findings of Porter \& Hector (1991) and Winans (1992) those who reported that the wounded sites are a common location for hairy root induction since they are used as a genetic transfer point for A. rhizogenes. The induced hairy roots of four fennel ecotypes were similar in terms of structure, coloration, and growth pattern (figure1, e).

\subsection{Effect of A. rhizogenes strains, ecotype and types of explant on hairy root induction}

In this experiment two parameters A. rhizogenes strain and various plant parts were measured to evaluate the hairy root induction efficiencies of fennel ecotypes. Analysis of variance (ANOVA) showed a significant difference among various ecotypes, explants and strains and their interactions for induction of hairy root percentage in fennel $(\mathrm{P}<0.01)$ (Table 1). All the strains of $A$. rhizogenes led to hairy root induction after 3-4 weeks of culture. However these A. rhizogenes strains were not equally efficient in hairy root induction percentage. Strain A4 conferred the highest induction percentage for all three explants examined and produced 50, 53 and $70 \%$ hairy root induction form leaf, cotyledon and hypocotyl, respectively (Figure 2).This hairy root induction percentage was followed by the strain TCC 15834, T4 and strain MSU respectively (Figure 2). Figure 2 indicates that strains A4 and ATCC 15834 were more competent than the other strains for hairy root induction in each explant type. Similarly, Arafa et al. (2015) reported that A4 was the best A. rhizogenes strain for transformed root induction in Nepeta cataria. In another report, the young leaves of Przewalskia tangutica showed highest sensitivity to A4 for the effectiveness $(100 \%)$ in the induction of hairy roots (Lan \& Quan, 2010). Further, ATCC 15834 has been also reported as a most widely used A. rhizogenes strain for strong root induction ability (Kochan et al., 2013; Kumar et al., 2014). Variation in hairy root induction among different bacterial strains could possibly attribute to disparity in virulence (Porter \& Hector, 1991).

In addition, types of explants also influenced the hairy root induction percentage in all strains (table 1). In present study, hypocotyls were reported more efficient with all strains of $A$. rhizogenes in hairy root production as compared to leaf and cotyledon (Figure 2). Similar results were reported by Lee et al. (2004) when these researchers conducted similar study in Taraxacum platycarpum. Findings of this study are contradictory to the findings of Hasnat et al. (2008) and Setamam et al. (2014) those who have reported higher hairy root induction from the cotyledonary regions of the Capsicum species. Previous findings indicated that A. rhizogenes strain and type of explants significantly influenced the induction of hairy root (Chaudhuri et al., 2005; Danphitsanuparn et al., 2012; Sudha et al., 2012).
Table 1 Mean squares of hairy root induction and hairy root induction frequency per single explant in fennel after one month

\begin{tabular}{|l|cc|c|}
\hline \multirow{2}{*}{ Source } & \multicolumn{3}{c|}{ Mean Square } \\
\cline { 3 - 4 } & df & $\begin{array}{c}\text { Hairy root } \\
\text { induction }\end{array}$ & $\begin{array}{c}\text { Hairy root } \\
\text { induction } \\
\text { frequency }\end{array}$ \\
\hline Ecotype & 3 & $661.583^{*}$ & $45.21^{\mathrm{ns}}$ \\
\hline Explant & 2 & $2747.299^{* *}$ & $6048.58^{* *}$ \\
\hline Strain & 3 & $22078.694^{* *}$ & $389.54^{* *}$ \\
\hline Ecotype * Explant * Strain & 18 & $438.046^{*}$ & $63.762^{\mathrm{ns}}$ \\
\hline Ecotype * Explant & 6 & $772.104^{*}$ & $46.120^{\mathrm{ns}}$ \\
\hline Explant * Strain & 6 & $1038.215^{* *}$ & $112.287^{* *}$ \\
\hline Ecotype * Strain & 9 & $56.645^{\mathrm{n} . \mathrm{s}}$ & $89.464^{*}$ \\
\hline Error & 96 & 207.264 & 38.299 \\
\hline
\end{tabular}

ns, not significant; *,** significant at 0.05 and 0.01 probability level.

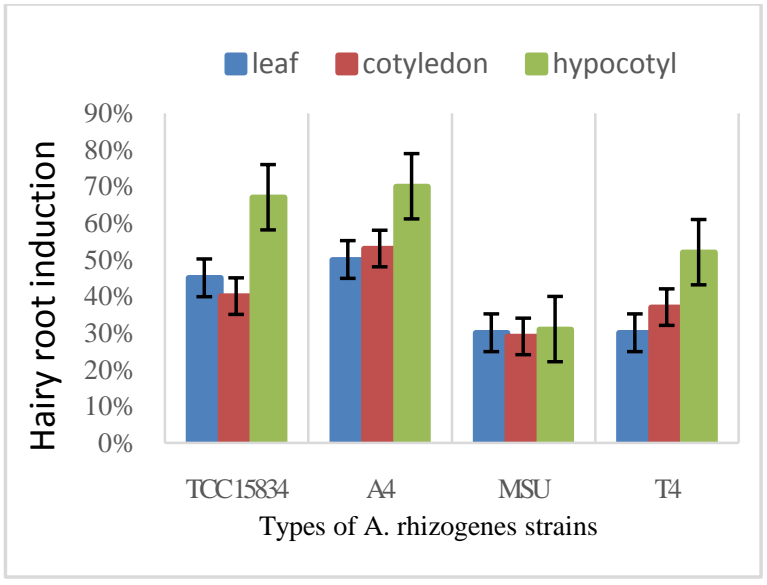

Figure 2 Effect of different $A$. rhizogenes strains on different explants for Percentages of hairy root induction per total explants $(\mathrm{n}=30)$ of $F$. vulgare after 1 month.

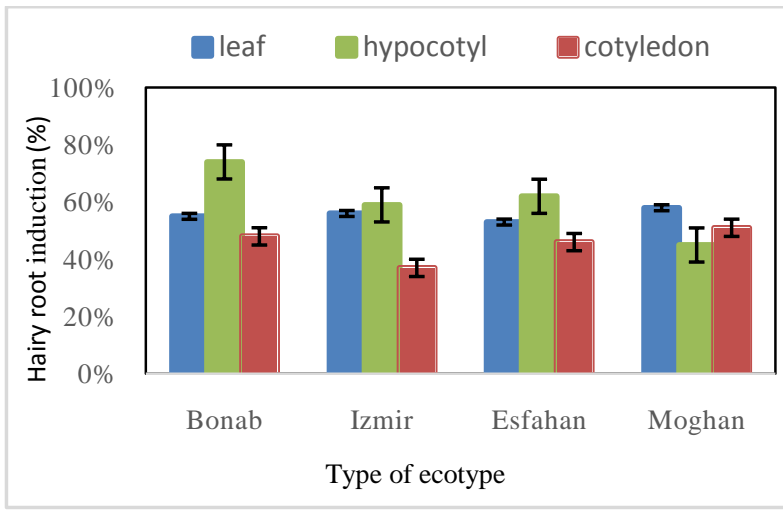

Figure 3 Effect of different A. rhizogenes strains on different ecotypes for Percentages of hairy root induction per total explants $(\mathrm{n}=30)$ of $F$. vulgare after 1 month.

Significant differences were observed between different ecotypes for hairy root induction percentage (table1). Results of this study showed that the hairy root induction percentage in Bonab were highest as compared to the other fennel ecotypes (Figure 3). 
Table 2 Effect of Agrobacterium strain, ecotype and explant on number of induced Hairy root per single explants (mean \pm standard deviation) in F.vulgare after 1 month

\begin{tabular}{|llcccc|}
\hline \multirow{2}{*}{ Ecotypes } & Explant type & \multicolumn{4}{c|}{ Strains } \\
\cline { 2 - 6 } Bonab & TCC 15834 & A4 & MSU & T4 \\
& Leaf & $27.66 \pm 0.57$ & $16.66 \pm 0.52$ & $13.33 \pm 0.57$ & $14.66 \pm 0.53$ \\
\cline { 2 - 6 } & Cotyledon & $8.66 \pm 0.45$ & $9.66 \pm 0.47$ & $3.66 \pm 0.81$ & $3.66 \pm 0.96$ \\
\cline { 2 - 6 } Izmir & Hypocotyl & $32.14 \pm 0.44$ & $25.33 \pm 0.54$ & $16.21 \pm 0.73$ & $25.33 \pm 0.50$ \\
\hline \multirow{3}{*}{ Esfahan } & Leaf & $36.66 \pm 0.57$ & $17.12 \pm 0.9$ & $14.66 \pm 0.53$ & $24.34 \pm 0.96$ \\
\cline { 2 - 6 } & Cotyledon & $7.32 \pm 0.62$ & $9.66 \pm 0.75$ & $4.66 \pm 0.93$ & $4.33 \pm 0.82$ \\
\cline { 2 - 6 } & Hypocotyl & $32.66 \pm 0.95$ & $10.66 \pm 0.98$ & $20.33 \pm 0.42$ & $23.41 \pm 0.52$ \\
\cline { 2 - 6 } & Leaf & $26 \pm 0.35$ & $30.15 \pm 0.99$ & $16.41 \pm 0.86$ & $15.22 \pm 0.79$ \\
\cline { 2 - 6 } & Cotyledon & $7.33 \pm 0.75$ & $9.51 \pm 0.65$ & $4.85 \pm 0.51$ & $4.66 \pm 0.67$ \\
\hline \multirow{3}{*}{ Moghan } & Hypocotyl & $24.66 \pm 0.67$ & $29.33 \pm 0.35$ & $12.33 \pm 0.65$ & $22.18 \pm 0.25$ \\
\cline { 2 - 6 } & Leaf & $16.66 \pm 0.79$ & $13.66 \pm 0.46$ & $10.66 \pm 0.97$ & $5.33 \pm 0.67$ \\
\cline { 2 - 6 } & Cotyledon & $7.46 \pm 0.83$ & $8.84 \pm 0.52$ & $6.36 \pm 0.64$ & $4.33 \pm 0.74$ \\
\cline { 2 - 6 } & Hypocotyl & $15.69 \pm 0.45$ & $15.05 \pm 0.56$ & $9.19 \pm 0.44$ & $10.30 \pm 0.56$ \\
\hline
\end{tabular}

Interaction between explants and ecotypes revealed a significant relationship between the hypocotyl and all ecotypes except Moghan and had high root induction percentage range from 59$74 \%$ (Figure 3). The leaf and cotyledons of all fennel ecotypes except Moghan showed hairy root induction between 37\% and $56 \%$. Leaf explants of Moghan ecotypes had the highest induction rate at $58 \%$ as compared to the leaf explants of other ecotypes
(Figures 3). The mean percentages for interaction between all ecotypes and A4 and ATCC 15834 strains were high at 66-83\% hairy root induction (Figure 4). These results of this study demonstrate that explant type and ecotype play an important role in hairy root induction. This may be because of the variation in the gene expression in various ecotypes (Winans, 1992; Konstantin et al., 2006). In this study, number of hairy roots in single explant

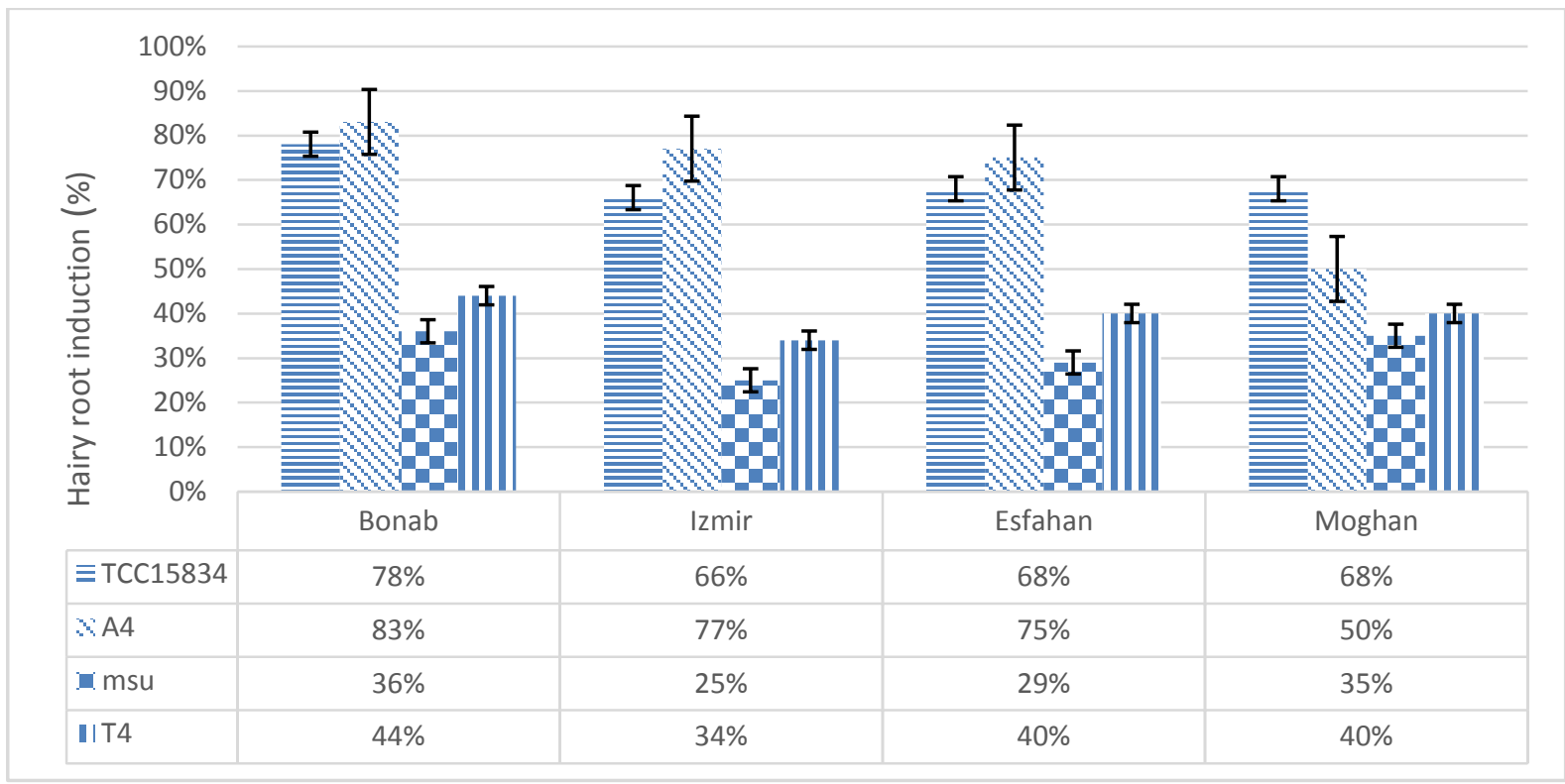

Figure 4 Effect of different explants on different ecotypes for Percentages of hairy root induction per total explants $(\mathrm{n}=30)$ of $F$. vulgare after 1 month. 
expressed the frequency of hairy root induction. The results of study suggested that explant types and strains of A. rhizogenes had significant differences in the number of hairy root induction (Table 1). Also the interactions between strains, explant and ecotypes were reported significant. The highest number of hairy roots was achieved for leaf and hypocotyl explants with ATCC 15834 strain in all ecotypes that flowed by A4 (Table 2). The cotyledonary explants showed least hairy root number in all strains and ecotypes. ATCC 15834 strain had the highest number of hairy roots for hypocotyl and leaf in all ecotypes (Table 2). Explant and strain specificity observed in the present study are in the agreement with the findings Sudha et al. (2003) and Setamam et al. (2014), those who reported that hypocotyl explants infected with strain ATCC 15834 gave maximum number of roots in Rauvolfia micrantha and C. frutescens respectively. However, ATCC 15834 showed the highest root induction in Izmir ecotype in leaf (37\%) and hypocotyl (33\%) explant (Table 2). Results showed that the hairy root induction number was high in the genotype Bonab with bacterial strain ATCC 15834 for hypocotyle and leaf explants with 33 and 28 respectively. While highest hairy root number was recorded for the ecotype Esfahan with leaf and hypocotyl explants along with bacterial strain A4 at 31(Table 2). Among the tested ecotypes, lowest hairy root number was reported from the ecotype Moghan inoculated with bacterial strain ATCC 15834 and A4 (Table 2). Several reports are available in family Apiaceae for their ability of producing hairy root; some species are potential candidates benefiting from this technique (Baranski, 2008).

\subsection{Confirmation of transgenic roots by PCR}

Total genomic DNA was extracted from normal roots, transformed hairy roots (explants were randomly selected from all ecotypes and bacterial strains treatments), and TpRi plasmid DNA was isolated from each A. rhizogenes strains as positive control for PCR analysis. PCR analysis was conducted using forward (FrolB) and reverse (RrolB) primers to confirm hairy roots. PCR successfully amplified rolB from the genomic DNA of all hairy root lines and bacterial plasmids (Figure 5). No amplification was detected in negative control $\mathrm{C}(-)$ as well as in the genomic DNA of non-transformed normal roots of $F$. vulgare ecotypes (lanes B, I, E and Mo) (Figure 5).

\section{Conclusion}

This is the first attempt to assess the effect of different $A$. rhizogenes strains and explant types on the induction of hairy root in $F$. vulgare from different ecotypes. Finding of this study suggest that A4 and ATCC 15834 were given the optimal hairy roots in fennel. Further, A4 had higher efficiency of root induction as compared with ATCC 15834, MSU and T4, while ATCC 15834 showed more hairy root induction number compared with A4, MSU and T4. Different

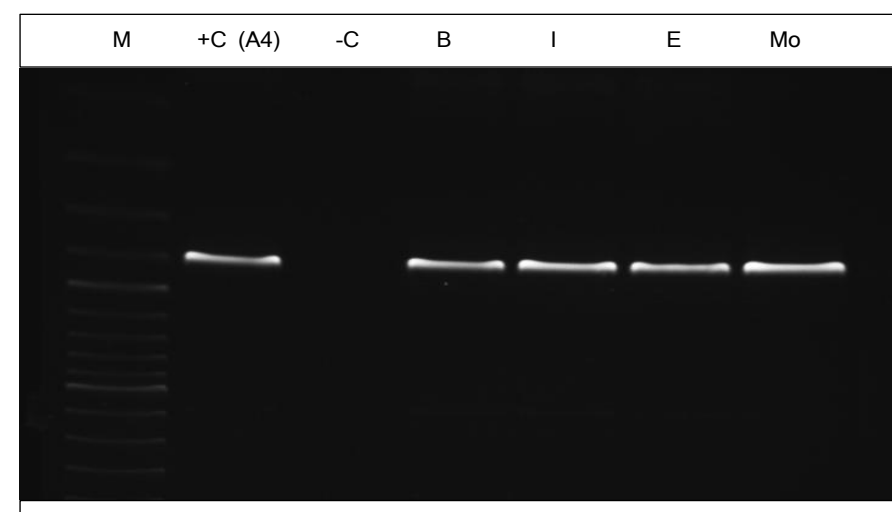
M
$+\mathrm{C}(\mathrm{A} 4)$
$-\mathrm{C}$
B
I
E
Mo

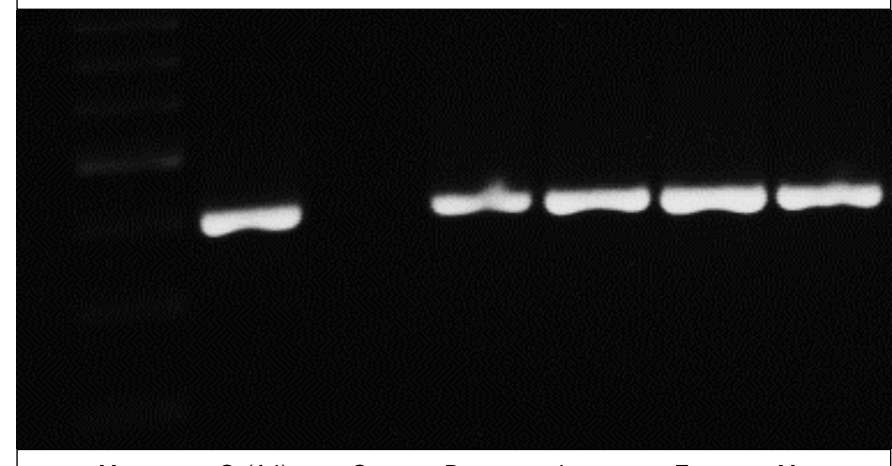

M

$+\mathrm{C}(\mathrm{A} 4)$

$-\mathrm{C}$

B

I

E

Mo

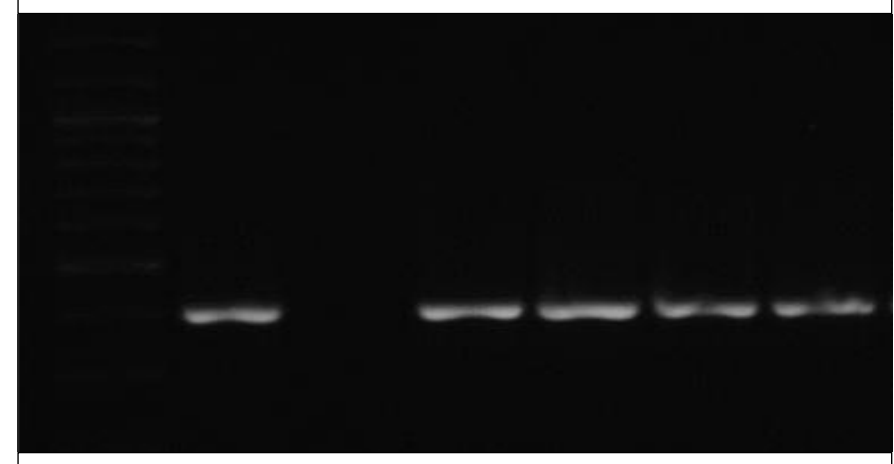

M

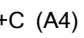

$-\mathrm{C}$

B

I

E

Mo

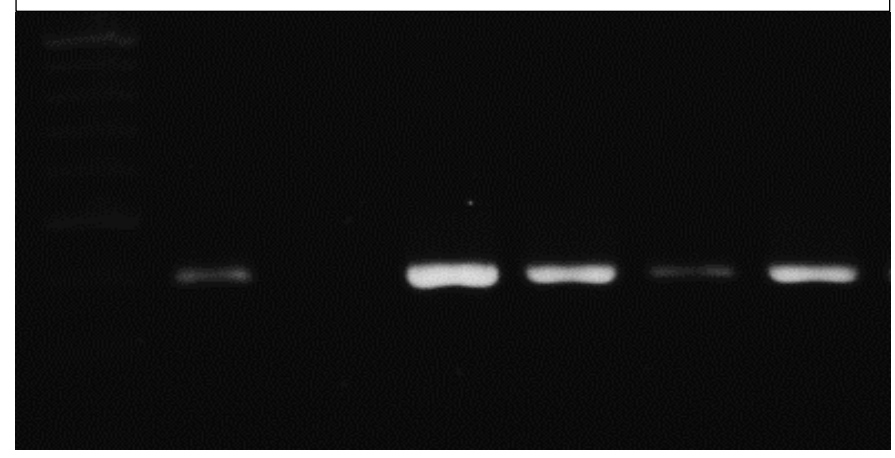

Fig 5 PCR amplification of 423 bp fragment of rolB gene using hairy root derived genomic DNA for all strains of Agrobacterium rizogenesis. Lane M 100-500 bp molecular weight marker; Lane $\mathrm{C}^{+} \mathrm{A4}$, TCC 15834, Msu and T4 Agrobacterium rhizogenes DNA (positive control), Lane C (-) DNA from non-transformed roots (negative control); Lane B, I, E and Mo hairy root lines DNA of Bonab, Izmir, Esfahan and Moghan ecotypes, respectively 
ecotypes showed almost similar results. However for each ecotype, suitable strain and explant was introduce for optimal hairy root induction. In ascending order, the most suitable explant types for maximum hairy root induction were hypocotyls, leaves and cotyledons. In present study transgenic hairy roots need to be further investigated for their potential as source of enhanced production of commercially important secondary metabolites and also for increasing specific medicinal products content by manipulation of the culture medium as well as precursor additions or elicitation (next paper). Also hairy root culture improved understanding of the biochemical pathways leading specific medicinal products synthesis will, in turn, be exploitable in manipulating and maximizing product synthesis under tissue culture and, ultimately, bioreactor conditions.

\section{References}

Alfermann AW, Petersen M (1995) Natural product formation by plant cell biotechnology-Results and perspectives. Plant Cell, Tissue and Organ Culture 43: 199-205. doi:10.1007/BF00052176

Arafa NM, Gabr AMM, Ibrahim MM, Shevchenko Y, Smetanska I (2015) Study the effect of hairy root transformation on rapid growth (growth morphology) of Nepeta cataria in vitro cultures. Journal of Innovations in Pharmaceuticals and Biological Sciences 2: 439-450.

http://jipbs.com/VolumeArticles/FullTextPDF/125_JIPBSV2I408. pdf

Baranski R (2008) Genetic transformation of carrot (Daucus carota) and other Apiaceae species. Transgenic plant, global $\begin{array}{llll}\text { science } & \text { books, } & \text { Pp. }\end{array}$ http://www.globalsciencebooks.info/Online/GSBOnline/images/08 06/TPJ_2(1)/TPJ_2(1)18-38o.pdf

Bensaddek L, Villarreal ML, Fliniaux MA (2008) Induction and growth of hairy roots for the production of medicinal compounds. Electronic Journal of Integrative Biosciences 1: 2-9.

Berlin J (1986) Secondary products from plant cell cultures. In: Rehm HJ, Reed G (Eds), Biotechnology a comprehensive treatise, Verlag Chemie, Verlagsgesellschaft, Weinheim 4: 630-658.

Birdane FM, Cemek M, Birdane YO, Gulcin I, Buyukokuroglu ME (2007) Beneficial effects of Foeniculum vulgare on ethanolinduced acute gastric mucosal injury in rats. World Journal of Gastroenterology 13(4): 607. doi: 10.3748/wjg.v13.i4.607

Chaudhuri KN, Ghosh B, Tepfer D, Jha S (2005) Genetic transformation of Tylophora indica with Agrobacterium rhizogenes A4: growth and tylophorine productivity in different transformed root clones. Plant Cell Reports 24: 25-35. Doi:10.1007/s00299004-0904-x

Danphitsanuparn P, Boonsnongcheep P, Boribonkaset T, Chintapakorn Y, Prathanturarug S (2012) Effect of Agrobacterium rhizogenes strains and other parameters on production of isoflavonoids in hairy roots of Pueraria candollei Grah. ex Benth. var. candollei. Plant Cell Tissue Organ Culture 111: 315-322. doi: 10.1007/s11240-012-0196-8

Davies KM, Deroles SC (2014) Prospects for the use of plant cell cultures in food biotechnology. Current Opinion in Biotechnology 26: 133-140. DOI:10.1016/j.copbio.2013.12.010

Delaram M, Kheiri S, Hodjati MR (2011) Comparing the effects of echinop hora-platyloba, fennel and placebo on pre-menstrual syndrome. Journal of Reproduction \& Infertility 12(3): 221-6. https://www.ncbi.nlm.nih.gov/pmc/articles/PMC3719290/

Garcia-Rodriguez MJ, Paupardin C, Saussay R (1978) Sur Ia formation d'un tissus secreteur et Iasynthesed'anethole par des tissus de Fenouil (Foeniculum vulgare Mill. var. dulce) cultives in vitro. Comptes-Rendus de l'Academie des Sciences 287: 693-696. DOI:10.1007/978-3-662-07770-2_12.

Hasnat R, Abbasi NA, Hafiz IA, Ahmed T, Chudhary Z (2008) Effect of different bacterial dilutions on transformation efficiency of hot chilli (Capsicum frutescens L.) varieties. Pakistan Journal of Botany 40: 2655-2662.

Hnnanlt G, Desmarest P, Du Manoir J (1989) Foeniculum vulgare Miller: Cell culture, regeneration, and the production of anethole. In: Bajaj YPS (Ed) Biotechnology in Agriculture and Forestry, Vol 7, Medicinal and Aromatic plants II, Springer Verlag, Berlin Heidelberg, 185-212.

Hu ZB, Du M (2006) Hairy root and its application in plant genetic engineering. Journal of Integrative Plant Biology 48: 121-127. DOI: 10.1111/j.1744-7909.2006.00121.x

Jamshidi E, Ghalavand A, Sefidkon F, Goltaph E (2012) Effects of different nutrition systems (organic and chemical) on quantitative and qualitative characteristics of Fennel (Foeniculum valgare Mill.) under water deficit stress. Iranian Journal of Medicinal And Aromatic Plants 28(2): 309-23. http://dx.doi.org/10.22092/ijrfpbgr.2016.106165

Kochan EM, Wasicela M, Sienkiewicz M (2013) The production of ginsenosides in hairy root cultures of American Ginseng, Panax quinquefolium L. and their antimicrobial activity. In Vitro Cellular \& Developmental Biology-Plant 49: 24-29. doi: 10.1007/s11627012-9469-5

Konstantin V, Kiseleva C, Mikhail L, Kusaykin B, Alexandra S (2006) The rolC gene induces expression of a pathogenesis-related $\beta$-1, 3-glucanase in transformed ginseng cells. Phytochemistry 67: 2225-2231. Doi: 10.1016/j.phytochem.2006.07.019

Kumar V, Desai D, Shriram V (2014) Hairy Root Induction in Helicteres isora L. and Production of Diosgenin in Hairy Roots. Natural Products and Bioprospecting 4:107-112. doi: 10.1007/s13659-014-0011-9 
Lan X, Quan H (2010) Hairy root culture of Przewalskia tangutica for enhanced production of pharmaceutical tropane alkaloids. Journal of Medicinal Plants Research 4: 1477-1481. Doi: 10.5897/JMPR09.289

Lee MH, Yoon ES, Jeong JH, Choi YE (2004) Agrobacterium rhizogenes-mediated transformation of Taraxacum platycarpum and changes of morphological characters. Plant Cell Reports 22: 822-827. Doi: 10.1007/s00299-004-0763-5

Setamam NM, Sidik NJ, Rahman ZA, Zain RM (2014) Induction of hairy roots by various strains of Agrobacterium rhizogenes in different types of Capsicum species explants. BMC Research Notes 7: 414. doi: 10.1186/1756-0500-7-414.

Moyano E, Fornale S, Palazon J, Cusido RM, Bonfill M, Morales C, Pinol MT (1999) Effect of Agrobacterium rhizogenes T-DNA on alkaloid production in Solanaceae plants. Phytochemistry 52: 1287-1292.

Murray MG, Thampson WF (1980) Rapid isolation of high molecular weight plant DNA. Nucleic Acids Research 8: 43214325. Doi: https://doi.org/10.1093/nar/8.19.4321

Nader BL, Taketa AT, Pereda-Miranda R, Villarreal ML (2006) Production of triterpenoids in liquid-cultivated hairy roots of Galphimia glauca. Planta Medica 72: 842-844. Doi 10.1055/s2006-931601.

Nagella P, Thiruvengadam M, Jung SJ, Murthy HN, Chung IM (2013) Establishment of Gymnema sylvestre hairy root cultures for the production of gymnemic acid. Acta Physiologiae Plantarum 35: 3067-3073. doi:10.1007/s11738-013-1327-5

Ooi CT, Syahida A, Stanslas J, Maziah M (2013) Efficiency of different Agrobacterium rhizogenes strains on hairy roots induction in Solanum mammosum. World Journal of Microbiology and Biotechnology 29: 421-430. Doi: 10.1007/s11274-012-1194-Z

Park SU, Facchini PJ (2000) Agrobacterium rhizogenes mediated transformation of opium poppy, Papaver somniferum 1., and California poppy, Eschscholzia californica Cham., root cultures. Journal of Experimental Botany 347: 1005-1016. Doi: 10.1093/jexbot/51.347.1005

Paupardin C (1976) One differentiation of secreting tissue and the formation of essential oil by plant tissue cultivated in vitro. $\mathrm{C} \mathrm{R}$ Congr Natl Soc Sav Sect Sci 101: 619-628.
Porter JR, Hector F (1991) Host range and implications of plant infection by Agrobacterium rhizogenes. Plant Science 10: 387-421.

Ravishankar GA, RamachandraRao S (2000) Biotechnological production of phyto-pharmaceuticals. The Journal of Biochemistry Molecular Biology and Biophysics 4: 73-102.

Sevon N, Oksman-Caldentey KM (2002) Agrobacterium rhizogene smediated transformation: root cultures as a source of alkaloids. Planta Medica 68: 859-868. Doi: 10.1055/s-2002-34924

Sharafi A, Sohi HH, Mirzaee H, Azadi P (2014) In vitro regeneration and Agrobacterium mediated genetic transformation of Artemisia aucheri Boiss. Physiology and Molecular Biology of Plants 20: 487-494. doi: 10.1007/s12298-014-0248-0

Sudha CG, Obul Reddy B, Ravishankar GA, Seeni S (2003) Production of ajmalicine and ajmaline in hairy root cultures of Rauvolfia micrantha Hook f., a rare and endemic medicinal plan. Biotechnology Letters 25: 631-636. Doi: 10.1023/A:1023012114628

Sudha CG, Sherina TV, Anand VP, Reji JV, Padmesh P, Sonia EV (2013) Agrobacterium rhizogenes mediated transformation of the medicinal plant Decalepis arayalpathra and production of 2hydroxy-4-methoxy benzaldehyde. Plant Cell, Tissue and Organ Culture 112: 217-226. Doi: 10.1007/s11240-012-0226-6

Thwe A, Arasu MV, Li X, Park ChH, Kim SJ, Al-Dhabi N, Park SU (2016) Effect of Different Agrobacterium rhizogenes Strains on Hairy Root Induction and Phenyl propanoid Biosynthesis in Tartary buckwheat (Fagopyrum tataricum Gaertn.). Frontiers in Microbiology 7: 318. doi: 10.3389/fmicb.2016.00318

Verpoorte R, Contin A, Memelink J (2002) Biotechnology for the production of plant secondary metabolites. Phytochemistry Reviews 1: 13-25. Doi: 10.1023/A:1015871916833

Winans SC (1992) Two-way chemical signaling in Agrobacteriumplant interaction. Microbiology Reviews 51: 12-31. https://www.ncbi.nlm.nih.gov/pmc/articles/PMC372852/

Yao Shch, Bai LH, Lan ZZ, Tang MQ, Zhai YJ, Huang H, Wei RCh (2016) Hairy root induction and polysaccharide production of medicinal plant Callery aspeciosa Champ. Plant Cell, Tissue and Organ Culture 126: 177-186. http://dx.doi.org/10.1007/s11240016-0988-3 